\title{
Who CARES? Interprofessional Competencies for Meeting the Complex Needs of Culturally and Linguistically Diverse Foster Youth With Disabilities
}

\author{
Tonika Duren Green \\ Sally G. Mathiesen
}

\begin{abstract}
This paper highlights effective interprofessional competencies for school professionals who are interested in improving the educational path of culturally diverse foster youth who are at risk of a disability or who have a disability. The interprofessional competencies were developed based on the lessons learned in the first three years of a federally funded grant. We propose cost-effective ways to address shortages of highly qualified school personnel to work with diverse foster youth with disabilities. Recommendations to improve practice with diverse foster youth with disabilities include increasing the number of Culturally Affirming and Responsive Education Specialists (CARES; school social workers, school counselors, and school psychologists) who are trained to respond to the educational and mental health needs of diverse foster youth with disabilities, who are culturally competent, who are advocates in schools, and who are skilled at interdisciplinary service delivery.
\end{abstract}

Keywords: Foster youth; foster care; child welfare; culture; disability

The foster care system represents the most vulnerable youth. Over 400,000 children in the United States are in foster care, with 75\% entering through reports of neglect and $25 \%$ entering through reports of child abuse (physical and/or sexual; U.S. Department of Health and Human Services Administration for Children and Families on Children, Youth and Families Children's Bureau (USDHHS 2014). One of the primary goals of the foster care system is to ensure children's safety, permanence, and well-being (Adoption and Safe Families Act, 1997; Child and Family Services Improvement and Innovation Act, 2011; Fostering Connections to Success and Increasing Adoptions Act, 2008; Preventing Sex Trafficking and Strengthening Families Act, 2014). Education is a critical component in assuring well-being, especially when instability and out-of-home placements lead students to experience frequent school transfers, disruptions to learning, and emotional insecurity (Clemens, Lalonde, \& Sheesley, 2016; Pecora, 2012).

While some youth in foster care blossom, the majority struggle and fail to thrive because of the lack of resources needed to develop in educational environments (Day, Riebschleger, Dworsky, Damashek, \& Fogarty, 2012; Ferguson \& Wolkow, 2012). This statement is especially true of school-aged children in foster care. Of the 400,000 youth in foster care in the United States, 62\% are school-aged (USDHSS, 2014; Foster Care and Education National Work Group, 2014). These youth experience withering educational outcomes. Over 78\% of students in foster care attend low-performing schools (Foster Care and Education National Work Group, 2014). Youth in the foster care system face adverse

Tonika Duren Green, Ph.D., is an Associate Professor, Department of Counseling and School Psychology at San Diego State University, San Diego, CA, 92182-1179 and Project Director of CARES. Sally Mathiesen, Ph.D., is a Full Professor, School of Social Work, San Diego State University, San Diego, CA, 92182-4119 and Project CARES Evaluator. 
conditions, including instability and school mobility, and for foster youth with disabilities, lack of access to least restrictive educational settings (Hill, 2013; Stone, \& Zibulsky, 2015). Students in foster care score $16-20 \%$ lower on statewide standardized achievement measures compared to students who are not in foster care (Foster Care and Education National Work Group, 2014; Stuart Foundation, 2011; Wiegmann, Putnam-Horstein, Barrat, Magruder, \& Needell, 2014). Fifty percent of students in foster care complete high school, and only $44 \%$ who graduate read at a high school level or higher (Day, Dworsky, \& Feng, 2013; Stuart Foundation, 2011). Thirty-five percent experience five or more school changes, and each school move results in a six-month loss of educational progress (Child Trends DataBank, 2015; Foster Care and Education National Work Group, 2014). These weak educational outcomes lead to poor post-secondary education, higher percentages of unemployment, incarceration, homelessness, and lower percentages of attaining a college degree (Foster Care and Education National Work Group, 2014; Legislative Analyst's Office of California, 2009; Snyder et al., 2016).

Poor results may intensify for children in foster care from culturally and linguistically diverse (CLD) backgrounds who also have disabilities. The term culturally and linguistically diverse foster youth with disabilities (CLDFYD) refers to children and youth in the foster care system "who may be distinguished (from mainstream culture) by ethnicity, social class, and/or language" and disability (Perez, 1998, p. 6). This triple whammy (being a foster child, from a diverse background, with a disability), can lead to severe challenges to school success. CLDFYD need educational advocates who are culturally affirming, accountable, collaborative, and skilled in prevention and intervention services to reduce achievement gaps, improve school stability, and improve the quality of special education services (Zetlin, 2006; Zetlin, Weinberg, \& Kimm, 2004). Educational advocates help to access or create resources to promote a healthy environment for growth. Unfortunately, no data sources that provide estimates of the number of CLDFYD and their educational and mental health outcomes currently exist.

This paper reviews what is known about the current outcomes and complex needs of CLDFYD. To highlight the unique characteristics of this population, the paper begins with a description of CLD foster youth and the disparities they face, then expands this discussion to include CLD foster youth with disabilities. The critical shortages of highly qualified professionals in school social work, school psychology, and school counseling needed to meet the needs of foster youth are presented, along with ways to respond to these shortages. The paper ends with a discussion of interdisciplinary strategies and competencies that encourage disciplines to work together to improve educational outcomes for children in foster care. The implications are relevant for all stakeholders who are responsible for academic and professional training relevant to the mental health and well-being of foster youth.

\section{Culturally and Linguistically Diverse Youth in Foster Care}

CLD youth are often overrepresented in foster care and in special education (Child Welfare Information Gateway, 2013; Hill, 2006). Hill (2006) examined several studies to determine the role of race in the child-protective services decision-making process and found that race was the "primary determinant" within reporting, investigation, 
substantiation, placement, and exit from care (Hill, 2006, p1). Reentry into the child welfare system was the only decision-making stage that did not reveal disparities across race and ethnicity.

African American youth make up over a third of the foster care population (Child Welfare Information Gateway, 2016; USDHHS, 2015). Their presence in foster care represents about twice their proportion in the general child population, resulting in a disproportionate representation of African American children in foster care (Child Welfare Information Gateway, 2016; Courtney, Barth, Berrick, \& Brooks, 1996; USDHHS, 2015). However, new reports show a decline in foster care among African Americans and an increase in foster care for other diverse groups (Child Welfare Information Gateway, 2016; USDHHS, 2015). According to a 2015 report from the U.S. Department of Health and Human Services Administration for Children and Families, Youth and Families, Children's Bureau (USDHHS), the total number of foster youth declined between 2005 and 2014; however, there was an increase in these numbers from 2013 to 2014. Table 1 displays the comparison of children from CLD backgrounds in the United States with those in foster care. Percentages with an asterisk represent an overrepresentation of that ethnic group in the foster care system compared to their representation in the U.S. population.

Table 1. Percentages of CLD Children in Foster Care 2015 (USDHHS, 2016)

\begin{tabular}{|c|c|c|}
\hline Ethnicity & US Children (73.6 million) & $\begin{array}{l}\text { Children in Foster Care } \\
(427,910)^{1}\end{array}$ \\
\hline African American & $14 \%(10.2$ million $)$ & $24 \% *(103,376)$ \\
\hline Asian & $5 \%(3.7$ million $)$ & $1 \%(2,232)$ \\
\hline Hispanic/Latino & $24 \%$ (18 million) & $21 \%(91,105)$ \\
\hline Native American & $1 \%(632,000)$ & $2 \%(10,5130)$ \\
\hline \multicolumn{3}{|c|}{$\begin{array}{l}\text { *represents higher percentage in foster care compared to percentage in general population } \\
\text { (disproportionality) } \\
{ }^{1} \text { Data from the AFCARS June 8, } 2016 \text { file submissions. Missing data are excluded from each table. } \\
\text { Therefore, the totals within each distribution may not equal the total provided for that subpopulation. } \\
\text { (USDHHS, 2016) }\end{array}$} \\
\hline
\end{tabular}

The number of CLD children in foster care continues to rise (USDHHS, 2015). Additionally, the outcomes of these youth remain stagnant (Child Welfare Information Gateway, 2016). Children in foster care from diverse backgrounds experience longer lengths of stay, remaining in foster care eight months longer on average than their nonCLD peers (Center for the Study of Social Policy, 2010; Child Welfare League of America, 2005; Summers, Wood, \& Donovan, 2013). CLD foster youth also experience lower rates of reunification (Center for Study of Social Policy, 2010; Child Welfare Information Gateway, 2013; USDHHS, 2015) and are more likely to become legal orphans because of high rates of re-entry into the system (Kimberlin, Anthony, \& Austin, 2009; USDHHS, 2006). Legal orphans are children who have not yet been adopted and have no legal permanent connection to their biological parents because the parents' rights have been terminated (Adams, 2010). CLD foster youth also experience less placement stability and achieve permanency less often or not as quickly (USDHHS Administration for Children and Families, 2013). 


\section{Addressing Disparities in Foster Care}

The need to address the overrepresentation of CLD children in child welfare has been discussed in the literature for four decades, but more prominently within the last ten years (Boyd, 2014; Child Welfare Information Gateway, 2013; Courtney et al., 1996; Courtney \& Skyles, 2003; Grossman, 1967; Hill, 2006). This problem has led stakeholders to consider whether inequality in child welfare practices and policies exists for CLD children and for what reasons (Child Welfare Information Gateway, 2013). Boyd (2014) describes a conceptual framework for understanding and explaining the pathways of African American disproportionality and disparity in child welfare. Boyd's framework acknowledges that many factors contribute to inequalities within child welfare. Boyd (2014) describes these factors as pathways including: (a) the disproportionate needs of African American children and their high exposure to overlapping risks (e.g., poverty, parent-child characteristics, community dynamics); (b) human decision-making, which includes the bias of culturally incompetent professionals who make important decisions about care; (c) agency-system issues that are saturated with institutionalized racism, policies, and infrastructures that exclude or limit services for African American children and youth; (d) placement dynamics, including the lack of support in kinship care, the length of stay in foster care, the quality of experience in foster care, lower rates of adoption, barriers to adoption, and the lack of stable placements; and (e) the lack of policies that specifically address the needs of African American children in foster care. Additionally, researchers are challenged to consider effective practices to reduce disproportionality and disparities in foster care across ethnic groups.

Recent literature on ways to address disparities and disproportionality in child welfare have considered culturally competent frameworks and evidence-based strategies in public agencies that serve foster youth (Center for Advanced Studies in Child Welfare, 2015). In the early literature on cultural competence, McPhatter (1997) introduced a Cultural Competence Attainment Model that encouraged professionals to pursue education about respecting cultures that are different from their own. This education model highlights the importance of accepting others' cultures and beliefs (Enlightened Consciousness), places an emphasis on strengths-based and resiliency approaches and de-emphasizes Eurocentric views and biases that exclude the voices and information from diverse communities (Grounded Knowledge Base), and shows the importance of self-reflection and evaluation to build and develop skills through a social justice framework (Cumulative Skill Proficiency). In the late 1990s and early 2000s, agencies developed cultural competence training initiatives based on McPhatter's model and other models of its kind to increase the number of culturally competent professionals (Boyle \& Springer, 2001; Weaver, 1999; Yan \& Wong, 2005). Despite these efforts, there continues to be a shortage of culturally competent professionals to meet the complex needs of CLD foster youth with disabilities.

Merkel-Holguin (2015) provides support for considering family group decisionmaking (FGDM) as a culturally responsive strategy in child welfare practice. FGDM has indigenous roots and recognizes the limits of Western approaches to serving families and children. A key feature of the model is to consider families as experts to ensure that the culture and values of specific groups are held in high honor and regard, which leads to effective practices (Merkel-Holguin, 2015). These practices include the inclusion of 
cultural brokers or coordinators who understand the values and cultural context of the families, giving families an active role in decision-making, and creating flexible environments and procedures that allow communities and families of color greater access to services (Al-Krenawi \& Graham, 2001).

Several other culturally competent strategies have emerged in the literature, including the Life Skills Parenting Programs and the Indian Positive Parenting Curriculum at the Denver Indian Family Resource Center (DIFRC) (Leake, 2007). DIFRC provides comprehensive services, including trauma-informed services, to Native populations. Their approach includes training service providers on the unique aspects of trauma and the multifaceted and multilayered impact of trauma on this population. This level of cultural awareness and responsive practices results in highly effective service delivery outcomes, including increased percentages of children placed with relative caregivers, increased reunification rates (higher than the national average), and positive changes in child wellbeing (Leake, 2007).

Several programs are designed to respond to the diverse needs of children in foster care and the disparities that exist in foster care. However, when the unique needs of children in foster care become more complex due to disabilities, there are limited resources and culturally competent practices to address these needs. In the next section, we discuss this triple whammy of being a CLDFYD, the outcomes these children face, and the challenges schools face to ensure educational success for these students. Disabilities are used broadly to include the 13 disability categories under the Individuals with Disabilities Education Act (IDEA, 2004). These disabilities are autism, deaf-blindness, deafness, emotional disturbance, hearing impairment, intellectual disability, multiple disabilities, orthopedic impairment, other health impairment, specific learning disability, speech and language impairment, traumatic brain injury, and visual impairment (IDEA, 2004).

\section{The Triple Whammy: Foster Youth from Culturally and Linguistically Diverse Backgrounds with Disabilities}

Approximately 30 to $40 \%$ of foster youth receive special education services, a percentage well above average for the general population (Hill, 2013; Larson \& Anderson, 2005). Foster children in special education are often unserved, underserved, overlooked, and ignored (Sullivan \& Knutsen, 2000; Zetlin, 2006). Foster youth with disabilities often experience multiple school placements, lost school records, and minimal interagency communication (Stuart Foundation, 2011; Zetlin, 2006). They are more likely to be in segregated special education classes and restrictive settings. They experience delayed or unimplemented Individualized Education Programs (IEPs) and have little access to quality mental health services (Stuart Foundation, 2011). As a result, these youth experience gaps in the delivery of needed special education services. These outcomes are partly the result of the lack of effectively trained school professionals who are prepared to respond to the diverse needs of CLDFYD (Boyd, 2014; Center for Advanced Studies in Child Welfare, 2015).

Kweisi Mfume argues that for CLDFYD, "education is a bridge over troubled water... not a guarantee of success but a precondition to survival" (Folman \& Anderson, 2003, p. 
2). Research that specifically addresses how to improve the educational conditions for CLD children in foster care with disabilities is scarce. The literature addresses parts of the triple risk, for example, CLD children with disabilities or foster youth with disabilities (Hill, 2013; Larson \& Anderson, 2005; Zetlin, 2006). When these characteristics exist in unison, the search for recent evidence-based research and strategies produces limited results. Leake, Black, and Roberts (2004) share essential tools to address challenges faced by CLD youth with disabilities who are in transition. Leake et al. (2004) highlight effective evidence-based programs that increase social skills, self-determination, expectations, financial resources, and access to education. More recently, the National Health Foundation (2013) published a report on the healthy development of minority youth with disabilities, with specific attention on youth in California. This report provides recommendations for meeting the needs of CLD youth with disabilities; however, foster youth issues are missing from the discussion. Schools are perplexed by the ways to best serve and educate CLD foster youth with disabilities (Center for Great Leaders for Teachers, 2014; Clemens et al., 2016; Folman \& Anderson, 2003; Hill, 2013; Staub \& Meighan, 2007).

There is an immediate need for related services personnel (school counselors, school psychologists, school social workers) who can respond to the complex social, emotional, and learning needs of diverse foster youth with disabilities or who are at risk of disabilities. In addition, professionals who accurately reflect the students they serve are critical in special education evaluation and assessment processes. These professionals stand in the gap and help to eradicate the "fast and furious track to special education" (Webb-Johnson, Green, \& Beard, 2008, p. 69). This accelerated track to special education happens when

students are placed in special education at disproportionate rates and without implementing effective interventions (Webb-Johnson, Green, \& Beard, 2008).

\section{CARES: A Response as the Remedy}

Project CARES (Culturally Affirming Responsive Education Specialist) is a five-year graduate program training grant initiated in 2012 by the U.S. Department of Education Office of Special Education Program (Green, 2012). This initiative was designed to respond to the need for quality services for CLD students with disabilities in foster care through four major goals:

1. To respond to the shortages of school psychologists, school counselors, and school social workers.

2. To increase the number of school psychologists, school counselors, and school social workers who are trained to provide high quality academic and mental health services known to be effective for CLD students in foster care with, or at risk of, disabilities.

3. To enhance the capacity of the programs to prepare professionals to work collaboratively to serve and advocate for these youth.

4. To disseminate best practices at conferences and workshops, in classrooms (e.g., case studies), and in our professional disciplines (e.g., professional papers). 
Project CARES' unique design includes: (a) an interdisciplinary approach, (b) a focus on children in foster care with or at risk of disabilities, and (c) a focus on training professionals who are highly qualified to impact students from ethnically and linguistically diverse backgrounds. The goal of the grant was to train 30 high-quality fully credentialed related services personnel (school counselors, school psychologists, and school social workers) prepared to serve high-need CLDFYD. Based on the lessons learned from the grant, the current paper highlights effective competencies for school professionals who are interested in improving the educational path of foster youth from diverse backgrounds who have or are at risk for a disability.

\section{Gaps in Care: Shortages of Highly-Qualified Professionals to Meet the Needs of CLDFYD}

Across the nation, there is a deepening shortage of school psychologists, school counselors, and school social workers prepared to serve CLD foster youth with disabilities (Boyle \& Springer, 2001; Center on Great Leaders for Teachers, 2014; Center on Personnel Studies in Special Education, 2004). According to Folman and Anderson (2003), there are a limited number of education professionals who have specialized training in working with students in foster care. Additionally, teachers, foster parents, and child welfare workers rarely interact to determine the best needs of the students (Folman \& Anderson, 2003). Schools have experienced significant shortages of these personnel for the past 10 years. Since 1996, school professionals, especially those who provide services for children with disabilities, represent personnel in the "considerable shortage" category among all fields in education (Müller, 2011, p. 3). They rank among the country's top labor shortage areas (National Coalition on Personnel Shortages in Special Education and Related Services [NCPSSERS], 2014). In some Western states, the shortages run deeper (NCPSSERS, 2014). California, with a population of over 37 million, has approximately 9,000 school counselors, 4,000 school psychologists, and 200 school social workers certified to serve children under the Individuals with Disabilities Education Act (IDEA, 2004), a law originally enacted by Congress in 1975 to ensure that children with disabilities have the right to a free appropriate public education (Lucile Packard Foundation for Children's Health, 2016). Personnel-to-student ratios exceed the maximum number suggested in all three disciplines, with the highest ratios for social workers. Table 2 displays the recommended ratios of school counselors, school psychologists, and school social workers to students and the actual ratios in the U.S.

Table 2. Recommended Versus Actual Ratios of Students to Personnel

\begin{tabular}{llll}
\hline $\begin{array}{l}\text { Related Services } \\
\text { Personnel }\end{array}$ & Maximum Ratio & U.S. Ratio & $\begin{array}{l}\text { Actual Ratio-U.S. } \\
\text { Largest State }\end{array}$ \\
\hline School Counselor & $1: 250$ & $1: 471$ & $1: 1016$ \\
School Psychologists & $1: 1000 / 1: 500^{1}$ & $1: 1383$ & $1: 1579$ \\
School Social Worker & $1: 250$ & $1: 2500$ & $1: 15256$ \\
\hline
\end{tabular}

${ }^{1}$ Full Service Recommended Ratio

(Sources: Lucile Packard Foundation for Children's Health, 2016; National Association of School Psychologists, 2010; National Association of Social Workers, 2016; U.S. Department of Education, National Center for Education Statistics, 2014) 
The most prominent shortages exist in high-needs schools with higher percentages of CLD students and students receiving free and reduced lunch (NCPSSERS, 2014). These schools experience the highest rates of turnover, unfilled positions, and educational achievement gaps. They also have the lowest rates of quality special education services and qualified personnel (Center on Personnel Studies in Special Education, 2004). NCPSSERS (2014) attributes these shortages to the increasing demand for services, a lack of highly qualified personnel to meet the demand, insufficient funding, and limited capacity of existing training programs to meet the demand.

The impact of these shortages may be summarized as follows: (a) fewer than one in five children in need of mental health services get the services they need; (b) students experience missing or incomplete services when qualified professionals are not available; (c) low-quality services are provided by unqualified personnel; (d) there are increased caseloads and workloads; (e) there is less opportunity for individual services; and (f) there are decreased opportunities to work collaboratively with school staff, students, and parents (NCPSSERS, 2014). Shortages of highly qualified professionals impede the ability of foster youth with disabilities to maximize their academic potential (NCPSSERS, 2014). The literature reveals a demand for more professionals of color (Grapin, Bocanegra, Green, Lee, \& Jaafar, 2016; Green, Cook-Morales, Robinson-Zañartu, \& Ingraham, 2009; Green \& Ingraham, 2005; Green, Tran, \& Young, 2005; McKellar \& Cowan, 2011; WebbJohnson et al., 2008). These professionals may help to stem the tide of discrimination, overrepresentation, and misidentification that students in foster care experience. In addition, professionals who accurately reflect the students they serve are critical in special education evaluation and assessment processes. The changing population of schools challenges the field of education to close the gaps and increase the number of school personnel to accurately reflect the level of need.

\section{CLDFYD Advocates}

School Counselors as Advocates. School counselors are on the front lines of working with children in schools. As advocates for students who are also in the foster care system, they can support youth and their families in obtaining effective resources that help to promote positive social and emotional well-being. School counselors can also help foster youth define long-term educational goals and develop effective decision-making for the future (American School Counselor Association, 2012). As foster youth advocates, school counselors can serve as liaisons between parents, guardians, teachers, courts, administrators, and the child. School counselors can also keep stakeholders informed about the academic progress of each child and arrange conferences when necessary. Additionally, school counselors hold a basic understanding of the social service system and are tasked to keep up with current educational laws related to foster youth.

School Social Workers as Advocates. School social workers have specialized training in mental health, behavior, academic support, consultation, and counseling techniques (School Social Work Association of America, 2014). As advocates for foster youth, school social workers can help to build strong and lasting partnerships between teachers and parents by advocating for ongoing school-family partnerships. They have the resources and training to connect students and families with community support services. They can help 
schools, parents/guardians, and teachers understand the unique behavioral and emotional needs of CLDFYD. School social workers can implement mental health and behavioral interventions to reduce absences and dropout rates and increase academic success (National Association of Social Workers, 2016). However, there are not enough school social workers in the field to meet the needs of the increasingly diverse population they serve (NCPSSERS, 2014). The need for school personnel to work collaboratively to meet these challenges is evident in this field.

School Psychologists as Advocates. School psychologists are uniquely qualified members of school teams who support students' ability to learn and teachers' ability to teach. They apply expertise in mental health, learning, and behavior to help children and youth succeed academically, socially, behaviorally, and emotionally (National Association of School Psychologists, 2015). School psychologists work together with students, families, teachers, and other school professionals to build and create safe and supportive learning environments that strengthen the home-school-community connection (National Association of School Psychologists, 2015).

School psychologists serve as advocates who identify foster youth who need support, help evaluate eligibility for special education services, and design and implement academic and behavior plans. As advocates for CLD children in foster care, school psychologists can help to ensure school stability. Their role is crucial in the development of services and supports addressing the negative impact that maltreatment and neglect can have on school performance (Staub \& Meighan, 2007). School psychologists can work with teachers to ensure that CLDFYD have a supportive and stable environment where they can feel safe and welcomed.

\section{Interdisciplinary Practice: Meeting the Complex Needs of CLD Foster Youth with Disabilities}

The complex nature of the issues that children in foster care face can be overwhelming for personnel who are not adequately trained to provide services for these youth. Children in the welfare system are at a higher risk of having or acquiring disabilities (Larson \& Anderson, 2005) and are often abused or neglected at higher rates than children in foster care without disabilities (3.4 times more likely). In a study conducted by Sullivan and Knutson (2000), 31\% of children with disabilities were found to have experienced maltreatment. Of these maltreatment cases, caseworkers reported that the presence of a disability was directly correlated with maltreatment for $47 \%$ of the children. Maltreatment coupled with the need for special services makes it challenging for personnel to respond, especially if they have not been trained adequately in working with this population. When diverse cultures are added to the equation, many personnel find themselves unprepared to address the issues. Professionals who work closely with foster youth (e.g., school counselors, school psychologists, and school social workers) should be knowledgeable regarding successful ways to work as a team to impact change for all foster youth. While each profession has its own set of professional competencies, little has been done in the area of interdisciplinary competency development, specifically for work with children in foster care (Ivanitskaya, Clark, Montgomery, \& Primeau, 2002). 


\section{Caring for CLDFYD: Competencies for Culturally Affirming and Responsive Education Specialist (CARES)}

Table 3 presents professional competencies designed to improve educational and mental health outcomes effectively for youth in foster care. These competencies build on the areas identified by child welfare and developmental disability professionals at the Institute for Human Services (IHS). The competencies delineate knowledge, skills, and practices that are essential in providing effective child welfare services to children in foster care from diverse backgrounds who have special needs. The competencies provide a blueprint for training highly qualified child welfare caseworkers and supervisors (Rycus, Freundlich, Hughes, Keefer, \& Oakes, 2006).

Competencies adopted from Merrell, Ervin, and Peacock (2012) are also included within this framework of competencies: (a) awareness of the nature, scope, complexity, and developmental trajectories of students in foster care with disabilities including behavioral, social, and mental health issues, (b) knowledgeable of effective interventions; (c) preparedness to interact with a multisystem of professionals (e.g., medical, clinical, and community care) that impact foster youth with disabilities; and (d) serve as experts in the application of data-oriented problem-solving approaches to the management of primary, secondary, and tertiary prevention and intervention efforts. Table 3 presents the combined interdisciplinary competencies from Merrell et al. (2012) and the research literature for school professionals in four major areas: (1) Effective Academic and Mental Health Services, (2) Educational and Parent Advocacy, (3) Cultural Competency, and (4) Interdisciplinary Service Delivery (Bridges, Davidson, Odegard, Maki, \& Tomkowiak, 2011; Merrell et al., 2012; Michael, Bernstein, Owens, Albright, \& Anderson-Butcher, 2014).

The CARES competencies encourage innovative ways for professionals to work together to improve outcomes for foster youth. They promote a collaborative effort that makes obsolete the old practices of doing work separately behind closed doors. Educational specialists with training in interdisciplinary prevention and intervention services help to enhance outcomes for foster youth and increase chances of school success (Bridges et al., 2011; Merrell et al., 2012; Michael et al., 2014).

\section{The Cost of CARES}

Funding the CARES interdisciplinary model might pose a challenge for some school districts, especially those with limited budgets. These budget shortfalls and the lack of capacity to implement this work can serve as a barrier to providing essential training and professional development. However, some districts have made great strides in addressing the needs of foster youth in schools. For example, in California, current personnel, many who are school counselors or school psychologists, are designated as foster care/educational liaisons for their school. Foster care liaisons are responsible for ensuring that children in care have their basic needs met, are safe, experience school stability, and gain access to education. Foster care liaisons receive ongoing professional development on issues impacting youth in foster care to improve their educational performance (AB 490, 2003; ESSA, 2015). 
Table 3. Interdisciplinary Competencies for Culturally Affirming and Responsive Education Specialists (CARES)

\begin{tabular}{|c|c|}
\hline Competency & $\begin{array}{l}\text { Interdisciplinary Competencies for Culturally Affirming and } \\
\text { Responsive Education Specialists (CARES) }\end{array}$ \\
\hline $\begin{array}{l}\text { Competency 1: } \\
\text { Effective Academic } \\
\text { and Mental Health } \\
\text { Services }\end{array}$ & $\begin{array}{l}\text { - CARES should understand the nature, scope, complexity, and } \\
\text { developmental trajectories of CLD students in foster care with or at } \\
\text { risk of disabilities (e.g., disproportionate placement in foster care } \\
\text { and special education). } \\
\text { - CARES implement and evaluate effective academic and mental } \\
\text { health services with CLD children in foster care with disabilities } \\
\text { and their families. } \\
\text { - CARES actively collaborate with key stakeholders (e.g., teachers, } \\
\text { principals, special education teachers, general education teachers, } \\
\text { and other team members) at assigned school-based fieldwork sites. }\end{array}$ \\
\hline $\begin{array}{l}\text { Competency 2: } \\
\text { Educational and } \\
\text { Parent Advocacy }\end{array}$ & $\begin{array}{l}\text { - CARES demonstrate knowledge of the child welfare system and } \\
\text { child advocacy, including culturally specific mandates. } \\
\text { - CARES actively collaborate with key stakeholders (e.g., teachers, } \\
\text { principals, special education teachers, general education teachers, } \\
\text { and other team members) at assigned school-based fieldwork sites. } \\
\text { - CARES develop an awareness of the need for self-care for } \\
\text { practitioners who work with underserved populations. }\end{array}$ \\
\hline $\begin{array}{l}\text { Competency 3: } \\
\text { Cultural Competency }\end{array}$ & $\begin{array}{l}\text { - CARES demonstrate knowledge and skills in working effectively } \\
\text { with foster children and their families from a variety of ethnic, } \\
\text { cultural, linguistic, economic, and religious backgrounds. } \\
\text { - CARES demonstrate an awareness of how school professionals' } \\
\text { own cultural frameworks/perspectives influence their work with } \\
\text { children and families from culturally and linguistically diverse } \\
\text { backgrounds. } \\
\text { - CARES are knowledgeable of the issues and impact of } \\
\text { disproportionate representation and overrepresentation in special } \\
\text { education of CLD students in foster care. } \\
\text { - CARES understand and use culturally relevant/affirming practices } \\
\text { to improve academic and mental health services for CLD children } \\
\text { with disabilities who are in foster care. }\end{array}$ \\
\hline $\begin{array}{l}\text { Competency 4: } \\
\text { Interdisciplinary } \\
\text { service delivery }\end{array}$ & $\begin{array}{l}\text { - Develop shared knowledge and skills in improving outcomes for } \\
\text { CLD foster youth with disabilities. } \\
\text { - Disseminate knowledge gained/learned to child welfare } \\
\text { professionals, parents, school staff, and other key stakeholders in } \\
\text { models supporting foster youth. } \\
\text { - Use interdisciplinary models for effective collaboration, teaming, } \\
\text { and group problem-solving to improve outcomes for CLD children } \\
\text { with disabilities in foster care. }\end{array}$ \\
\hline
\end{tabular}

(Sources: LaLiberte \& Lightfoot, 2013; Lewallen, Hunt, Potts-Datema, Zaza, \& Giles, 2015; Merrell et al., 2012; Rycus et al., 2006; Rycus \& Hughes, 2000)

With the recent reauthorization of the Elementary and Secondary Education Act of 1965 (ESEA), now called the Every Student Succeeds Act (ESSA, 2015), all state 
education agencies are required by law to have a foster youth liaison. In addition, states are mandated to track the achievement and graduation rates for children in foster care. This is the first time that ESSA has included protections and services for foster youth and collaboration with child welfare services to promote educational success and school stability (Hults \& Burdick, 2016). Under ESSA, local education agencies receiving Title I funds must work with child welfare agencies to implement clear plans to ensure school stability, including transportation. This Title I funding can also be used to hire qualified personnel to provide comprehensive learning supports and other interventions (i.e., mental health, academic interventions, and behavioral interventions). ESSA references these highly qualified personnel as specialized instructional support personnel (SISP). SISPs are school counselors, school social workers, school psychologists, and other qualified related personnel with specialized training to meet the unique needs of school-aged foster youth. Many of these personnel work in schools across several states (e.g., California, Florida, Massachusetts, Nevada, Pennsylvania, and Rhode Island; Center on Great Leaders for Teachers, 2014).

Schools can also partner with local universities to enlist the support of graduate programs that train degree-seeking students to become specialized instructional support personnel. Students can serve as interns within the district to provide support to schools in need. This could be a cost-effective way of obtaining comprehensive support. It would also provide the intern with specialized practical and hands-on training. Additionally, parents and other stakeholders may be willing to serve as volunteers to help schools meet the unique needs of children in foster care with disabilities.

Funding streams such as training grants and other federally funded and non-federally funded state and national grant initiatives can provide support to ensure the educational success of foster youth. School professionals can work together to develop sound proposals. However, to date, there is no consistent funding source that has the goal of training school professionals to meet the needs of CLDFYD. Project CARES is one funding success story that garnered the support needed to build a successful interdisciplinary training program, but the funding ends in 2017. There is some promise in California with the recent passage of the Local Control Funding Formula (LCFF) (California Department of Education, 2013), a new school funding law that gives districts funding to provide greater resources to serve low-income students, English learners, and students in foster care. However, school districts have had difficulty demonstrating progress toward annual goals and implementing actions to achieve these goals. This funding source could potentially be the stepping stone to train highly qualified CARES personnel across the nation.

\section{Future Directions and Implications}

Schools districts are facing enormous challenges in knowing how best to serve and educate CLDFYD in their schools. A critical issue in educating CLDFYD is the lack of highly qualified personnel who can work collaboratively with teachers, parents, and other stakeholders to ensure educational success of these youth. CARES addresses the national need to recognize who CLDFYD are in schools, how they learn best, and ways to implement culturally affirming practices to support academic success. CARES responds to 
ESSA's call for specialized instructional support personnel who are highly qualified to provide comprehensive services (e.g., school-wide support, academic interventions, behavioral interventions, and mental health support) (ESSA, 2015). CARES seeks to address the triple whammy through culturally competent interdisciplinary practices that encourage school professionals to work together, instead of in silos, to provide school stability and achievement for CLDFYD.

Youth in the foster care system have a complex set of needs that can best be addressed by culturally affirming interdisciplinary teams. The work begins with university training programs and other professional development programs that have a vested interest in producing culturally competent professionals across disciplines. Interdisciplinary teams address the myriad needs that arise, differentiating interventions based on their specializations. Thus, early training for work in an interdisciplinary setting helps professionals understand how to address the needs of foster youth and improve educational outcomes (Strand, 2006). Training and professional development programs that infuse the aforementioned competencies (academics, mental health, and parent educational advocacy) in their clinical practices help prepare professionals for interdisciplinary work. Interdisciplinary practice creates effective learning that is more holistic than individualized knowledge-based practice (Ivanitskaya et al., 2002). This practice provides school professionals with cross-disciplinary knowledge and evidence-based practices for CLDFYD. Ivanitskaya et al. (2002) completed a comprehensive review of the literature and found that interdisciplinary learning and practice models yielded the following predicted outcomes: (a) flexible thinking; (b) understanding of strengths and limitations of thinking; (c) ability to assess; (d) value of the knowledge; (e) improved content retention, enhanced thinking and learning skills and enlarged perspectives; and (f) the ability to synthesize or integrate. The model empowers professionals to develop new competencies that are shared between the professions and that reflect contributions of one discipline to another.

The work ahead encourages professionals to work together, embrace what they learn from one another, and acknowledge the value that each profession brings to the table. School social workers can play a leadership role in creating and coordinating interprofessional teams. Interdisciplinary practice and competency development ensure that children and youth in foster care get the educational, mental, and physical support they need to grow and blossom.

\section{References}

AB 490. (2003). An act to amend Sections 48645.5, 48850, 48859, 49061, 49069.5, 49076, and 56055 of, and to add Sections 48853 and 48853.5 to, the Calif. Educ. Code, and to amend Sections 361, 366.27, 726, 727.2, 4570, 16000, and 16501.1 of the Calif. Welf. and Instit. Code, relating to minors.

Adams, L. T. (2010). Resurrecting parents of legal orphans: Un-terminating parental rights. Virginia Journal of Social Policy and the Law, 17(2), 318-372. 
Adoption and Safe Families Act of 1997, P.L. 105-89, 111 Stat. 2115, signed into law November 19, 1997, amending titles IV-B and IV-E of the Social Security Act. Retrieved from https://www.congress.gov/bill/105th-congress/house-bill/867

Al-Krenawi, A., \& Graham, J. R. (2001). The cultural mediator: Bridging the gap between a non-western community and professional social work practice. British Journal of Social Work, 31(5), 665-685. doi:https://doi.org/10.1093/bjsw/31.5.665

American School Counselor Association. (2012). ASCA national model: A framework for school counseling programs. Alexandria, VA: American School Counselor Association.

Boyd, R. (2014). African American disproportionality and disparity in child welfare: Toward a comprehensive conceptual framework. Children and Youth Services Review, 37, 15-27. doi:https://doi.org/10.1016/j.childyouth.2013.11.013

Boyle, D. P., \& Springer, A. (2001). Toward a cultural competence measure for social work with specific populations. Journal of Ethnic and Cultural Diversity in Social Work, 9(3-4), 53-71. doi:https://doi.org/10.1300/J051v09n03_03

Bridges, D. R., Davidson, R. A., Odegard, P. S., Maki, I. V., \& Tomkowiak, J. (2011). Interprofessional collaboration: Three best practice models of interprofessional education. Medical Education Online, 16. doi:https://doi.org/10.3402/meo.v16i0.6035

California Department of Education. (2013). Local control funding formula overview: Information about the funding and accountability provisions of the local control funding formula. Retrieved from http://www.cde.ca.gov/fg/aa/lc/lcffoverview.asp

Center for Advanced Studies in Child Welfare, School Social Work University of Minnesota. (2015). Culturally Responsive Child Welfare Practices CW360 ${ }^{\circ}$ Comprehensive look at a prevalent child welfare issue. Retrieved from http://cascw.umn.edu/wp-content/uploads/2015/03/CW360-Winter2015.pdf

Center for the Study of Social Policy. (2010). Positive outcomes for all: Using an institutional analysis to identify and address African American children's low reunification rates and long-term stays in Fresno County's foster care system. Retrieved from http://www.cssp.org/pdfs/positive_outcomes_fresno_co_institutional_analysis.pdf

Center on Great Leaders for Teachers. (2014). Examples of state regulations governing specialized instructional support personnel evaluations. Retrieved from http://www.gtlcenter.org/content/examples-state-regulations-governing-specializedinstructional-support-personnel-evaluations

Center on Personnel Studies in Special Education. (2004). Retaining qualified special education teachers: Understanding why teachers leave and what school districts can do about it. Special Education Workforce Watch: Insights from Research. Gainesville, FL: Author. 
Child and Family Services Improvement and Innovation Act, 2011, Pub. L. No. 112-34. H.R. 2883. (2011). Retrieved from https://www.congress.gov/bill/112thcongress/house-bill/2883

Child Trends Data Bank. (2015). Foster youth: Indicators on children and youth. Retrieved from http://www.childtrends.org/wpcontent/uploads/2014/07/12 Foster Care.pdf

Child Welfare Information Gateway [CWIG]. (2013). Addressing racial disproportionality in child welfare (Issue Brief). Washington, DC: Author. Retrieved from https://www.childwelfare.gov/pubPDFs/racial_disproportionality.pdf

CWIG. (2016). Foster cares statistics 2014. Retrieved from https://www.childwelfare.gov/pubPDFs/foster.pdf

Child Welfare League of America. (2005). Children of color in the child welfare system. National Data Analysis System. Retrieved from http://thehill.com/images/stories/whitepapers/pdf/ChildrenofColor05.pdf

Clemens, E. V., Lalonde, T. L., \& Sheesley, A. P. (2016). The relationship between school mobility and students in foster care earning a high school credential. Children and Youth Services Review, 68, 193-201. doi:https://doi.org/10.1016/j.childyouth.2016.07.016

Court Appointed Special Advocates for Children. (2013). Seven important facts CASA/GAL volunteers need to know when advocating for children of color. Retrieved from http://www.casaforchildren.org/site/c.mtJSJ7MPIsE/b.6561107/

Courtney, M. E., Barth, R. P., Berrick, J. D., \& Brooks, D. (1996). Race and child welfare services: Past research and future directions. Child Welfare, 75(2), 99-137.

Courtney, M., \& Skyles, A. (2003). Racial disproportionality in the child welfare system. Children and Youth Services Review, 25(5), 355-358. doi:https://doi.org/10.1016/S0190-7409(03)00025-2

Day, A., Dworsky, A., \& Feng, W. (2013). An analysis of foster care placement graduation rates. Research in Higher Education Journal, 19, 1-17.

Day, A., Riebschleger, J., Dworsky, A., Damashek, A., \& Fogarty, K. (2012). Maximizing educational opportunities for youth aging out of foster care by engaging youth voices in a partnership for social change. Children and Youth Services Review, 34(5), 1007-1014. doi:https://doi.org/10.1016/j.childyouth.2012.02.001

Elementary and Secondary Education Act. Pub. L. 89-10, 79 Stat. 77, 20 U.S.C. ch.70. (1965).

Every Student Succeeds Act of 2015, Pub. L. No. 114-95, 129 Stat. 1802. U.S.C. 6301. The ESSA includes the most recent amendments to the and Secondary Education Act of 1965. Retrieved from https://www.congress.gov/congressional-report/114thcongress/house-report/354/1 
Ferguson, H. B., \& Wolkow, K. (2012). Educating children and youth in care: A review of barriers to school progress and strategies for change. Children and Youth Services Review, 34(6), 1143-1149. doi:https://doi.org/10.1016/j.childyouth.2012.01.034

Folman, R., \& Anderson, G. (2003). Troubled water foster care youth and college: Educational challenges for foster care and youth aging out of care. Michigan State University, School of Social Work. Retrieved from file:///C:/Users/vdecker/Downloads/troubledwater_final.pdf

Foster Care and Education National Work Group. (2014). Research highlights on education and foster care. Retrieved from http://www.fostercareandeducation.org/DesktopModules/Bring2mind/DMX/Downlo ad.aspx ?EntryId=1933\&Command=Core_Download\&method $=$ inline $\&$ PortalId $=0 \& T$ $\mathrm{abId}=124$

Fostering Connections to Success and Increasing Adoptions Act of 2008, Pub. L. No. 110-351, 122 Stat. 3939. Retrieved from https://www.gpo.gov/fdsys/pkg/PLAW110publ351/pdf/PLAW-110pub1351.pdf

Grapin, S. L., Bocanegra, J. O., Green, T. D., Lee, E. T., \& Jaafar, D. (2016). Increasing diversity in school psychology: Uniting the efforts of institutions, faculty, students, and practitioners. Contemporary School Psychology, 20(4), 345-355. doi:https://doi.org/10.1007/s40688-016-0092-Z

Green, T. D. (2012). SDSU Interdisciplinary Collaborative to Prepare Culturally Affirming and Responsive Education Specialists (CARES) to Improve Outcomes for Foster Youth with Disabilities. U.S. Department of Education, Office of Special Education Programs (No. H325K120418), Personnel Preparation Grant, \$1.25 million.

Green, T. D., Cook-Morales, V. J., Robinson-Zañartu, C. A., \& Ingraham, C. L. (2009). Pathways on a journey to getting it: Multicultural competence training and continuing professional development. In J. Jones (Ed.), The psychology of multiculturalism in schools: A primer for practice, training, and research (pp. 83-113). Bethesda, MD: National Association of School Psychologists.

Green, T. D., \& Ingraham, C. L. (2005). Multicultural education. In S. Lee (Ed.), Encyclopedia of School Psychology (pp. 338-342). Thousand Oaks, CA: Sage. doi:https://doi.org/10.4135/9781412952491.n181

Green, T. D., Tran, M., \& Young, R. (2005). The impact of ethnicity, SES, language, and training program on teaching choice among new teachers in California. The Bilingual Research Journal, 29, 583-598. doi:https://doi.org/10.1080/15235882.2005.10162853

Grossman, S. J. (1967). Child of a different color: Race as a factor in adoption and custody proceedings. Buffalo Law Review, 17, 303-348. 
Hill, K. (2013). Special education experience of older foster youth with disabilities: An analysis administrative data. Journal of Public Child Welfare, 7(5), 520-535. doi:https://doi.org/10.1080/15548732.2013.843493

Hill, R. B. (2006). Synthesis of research on disproportionality in child welfare: An update. Casey-CSSP Alliance for Racial Equity in the Child Welfare System. Retrieved from http://www.cssp.org/reform/child-welfare/other-resources/synthesisof-research-on-disproportionality-robert-hill.pdf

Hults, R. V., \& Burdick, K. (2016). Federal education law delivers vital protections for foster youth. Youth Today. Retrieved from http://youthtoday.org/2016/02/federaleducation-law-delivers-vital-protections-for-foster-youth/

Individuals With Disabilities Education Act, Pub. L. No. 108-446, 20 U.S.C. § 1400. (2004).

Ivanitskaya, L., Clark, D., Montgomery, G., \& Primeau, R. (2002). Interdisciplinary learning: Process and outcomes. Innovative Higher Education, 27(2), 95-111. doi:https://doi.org/10.1023/A:1021105309984

Kimberlin, S. E., Anthony, E. K., \& Austin, M. J. (2009). Re-entering foster care: Trends, evidence, and implications. Children and Youth Services Review, 31(4), 471-481. doi:https://doi.org/10.1016/j.childyouth.2008.10.003

LaLiberte, T. L., \& Lightfoot, E. (2013). Breaking down the silos: Examining the intersection between child welfare and disability. Journal of Public Child Welfare, 7(5), 471-479. doi:https://doi.org/10.1080/15548732.2013.865962

Larson, S. A., \& Anderson, L. (2005). Children with disabilities and the child welfare system: Prevalence data. Impact: Feature Issue on Children with Disabilities in the Child Welfare System, 19(1), 6-7. Retrieved from http://ici.umn.edu/products/impact/191/over6.html

Leake, D. W., Black, R. S., \& Roberts, K. (2004). Assumptions in transition planning: Are they culturally sensitive? Impact: Feature Issue on Achieving Postsecondary Education and Transition Results for Students with Disabilities, 16(3), 28-29. Retrieved from https://ici.umn.edu/products/impact/163/163.pdf

Leake, R. B. (2007). Denver Indian Family Resource Center: Research Report. Rocky Mountain Quality Improvement Center (Grant \# 90-CA-1699). Retrieved http://www.americanhumane.org/assets/pdfs/children/pc-rmqic-dif-report.pdf

Legislative Analyst's Office of California. (2009). Education of foster youth in California. Retrieved from http://www.lao.ca.gov/Publications/Detail/2069

Lewallen, T. C., Hunt, H., Potts-Datema, W., Zaza, S., \& Giles, W. (2015). The whole school, whole community, whole child model: A new approach for improving educational attainment and healthy development for students. Journal of School Health, 85(11), 729-739. doi:https://doi.org/10.1111/josh.12310 
Lucile Packard Foundation for Children's Health. (2016). Number of pupil support service personnel by type of personnel. Retrieved from http://www.kidsdata.org/data/topic/table/pupil-support-number-type.aspx

McKellar, N., \& Cowan, K. C. (2011). Supporting students in foster care. Principal Leadership, 12(1), 12-16. Retrieved from https://www.nasponline.org/Documents/Resources\%20and\%20Publications/Handout s/Families\%20and\%20Educators/Foster_Children_Sept\%202011.pdf

McPhatter, A. R. (1997). Cultural competence in child welfare: What is it? How do we achieve it? What happens without it? Child Welfare, 76(1), 255-278.

Merkel-Holguin, L. (2015). Family group decision making as a culturally responsive child welfare practice. Culturally Responsive Child Welfare Practices CW360 Comprehensive look at a prevalent child welfare issue, p. 19. Center for Advanced Studies in Child Welfare, School Social Work University of Minnesota. Retrieved from http://cascw.umn.edu/wp-content/uploads/2015/03/CW360-Winter2015.pdf

Merrell, K., Ervin, R. A., \& Peacock, G. G. (2012). School psychology for the 21st century: Foundations and practices ( $2^{\text {nd }} \mathrm{ed}$.). NY: Guilford.

Michael, K. D., Bernstein, S., Owens, J. S., Albright, A., \& Anderson-Butcher, D. (2014). Preparing school mental health professionals: Competencies in interdisciplinary and cross-system collaboration. In M. D. Weist, N. A. Lever, C. P. Bradshaw, J. S. Owens (Eds.), Handbook of school mental health (pp. 31-43). Springer US: NY. doi:https://doi.org/10.1007/978-1-4614-7624-5 3

Müller, E. (2011). Information from the national data sources related to personnel shortages in special education and related services. Personnel Improvement Center Practice brief: National Center to Improve Recruitment and Retention of Qualified Personnel for Children with Disabilities.

National Association of School Psychologists [NASP]. (2010). Model for comprehensive and integrated school psychological services. Retrieved from https://www.nasponline.org/Documents/Standards\%20and\%20Certification/Standard s/2 PracticeModel.pdf

NASP. (2015). Who are school psychologists? Retrieved from https://www.nasponline.org/about-school-psychology/who-are-school-psychologists

National Association of Social Workers. (2016). NASW standards for school social work services. Retrieved from http://www.naswdc.org/practice/standards/NASWSchoolSocialWorkStandards.pdf

National Coalition on Personnel Shortages in Special Education and Related Services. (2014). Special education personnel shortages factsheet. Retrieved May 6, 2016, from http://specialedshortages.org/wp-content/uploads/2014/03/NCPSSERS-Fact$\underline{\text { Sheet.pdf }}$ 
National Health Foundation. (2013). Final report healthy youth development: Reaching California's minority youth with disabilities. Retrieved from http://www.acphd.org/media/318892/final-report_health_youth_dev.pdf

No Child Left Behind Act of 2001, 20 U.S.C. $§$ 6319. (2008).

Pecora, P. J. (2012). Maximizing educational achievement of youth in foster care and alumni: Factors associated with success. Children and Youth Services Review, 34(6), 1121-1129.

Perez, B. (1998). Sociocultural contexts of language and literacy. Mahwah, NJ: Lawrence Erlbaum.

Preventing Sex Trafficking and Strengthening Families Act, 2014. Pub. L. No. 113-183. H.R. 4980. Retrieved from https://www.congress.gov/bill/113th-congress/house$\underline{\text { bill } / 4980}$

Rycus, J. S., Freundlich, M., Hughes, R. C., Keefer, B., \& Oakes, E. J. (2006). Confronting barriers to adoption success. Family Court Review, 44(2), 210-230. doi:https://doi.org/10.1111/j.1744-1617.2006.00081.x

Rycus, J. S., \& Hughes, R. C. (2000). What is competency-based inservice training? Columbus, OH: Institute for Human Services. Retrieved from http://www.ihsTRAINet.com/TRAINet/resources.htm

School Social Work Association of American. (2014). http://www.sswaa.org/

Snyder, S. M., Hartinger-Saunders, R., Brezina, T., Beck, E., Wright, E. R., Forge, N., \& Bride, B. E. (2016). Homeless youth, strain, and justice system involvement: An application of general strain theory. Children and Youth Services Review, 62, 90-96. doi:https://doi.org/10.1016/j.childyouth.2016.02.002

Staub, D., \& Meighan, M. (2007). Improving educational success for children and youth in foster care: Ensuring school stability. NASP Communiqué, 30(4). Retrieved from http://www.nasponline.org/publications/cq/index.aspx? vol=36\&issue $=4$

Stone, S., \& Zibulsky, J. (2015). Maltreatment, academic difficulty, and systemsinvolved youth: Current evidence and opportunities. Psychology in the Schools,52(1), 22-39. doi:https://doi.org/10.1002/pits.21812

Strand, V. C. (2006). Interdisciplinary training for effective implementation of services in response to a social policy change. Journal of Human Behavior in the Social Environment, 13(4), 37-53.

Stuart Foundation. (2011). First look: Foster youth education outcomes in four California counties. San Francisco, CA: Stuart Foundation. Retrieved from http://stuartfoundation.org/first-look-foster-youth-education-outcomes-fourcalifornia-counties/

Sullivan, P. M., \& Knutson, J. F. (2000). Maltreatment and disabilities: A populationbased epidemiological study. Child Abuse \& Neglect, 24(10), 1257-1273. doi:https://doi.org/10.1016/S0145-2134(00)00190-3 
Summers, A., Wood, S., \& Donovan, J. (2013). Disproportionality rates for children of color in foster care 2013: Technical assistance bulletin. National Council of Juvenile and Family Court Judges. Retrieved from http://www.ncjfcj.org/resourcelibrary/publications/disproportionality-rates-children-color-foster-care-2013technical

U.S. Department of Education, National Center for Education Statistics. (2014). United States student to school counselor ratios. Retrieved from https://www.schoolcounselor.org/asca/media/asca/home/Ratios13-14.pdf

U.S. Department of Health and Human Services, Administration for Children and Families, Administration on Children, Youth, and Families, Children's Bureau [USDHHS]. (2006). AFCARS Report \#13: Preliminary FY 2005 Estimates as of September 2006. Retrieved from http://www.acf.hhs.gov/programs/cb/stats_research/afcars/tar/report13.htm

USDHHS. (2013). Child welfare outcomes: Report to Congress safety permanency wellbeing.

USDHHS. (2014). Child maltreatment: 25th year of reporting. Retrieved from https://www.acf.hhs.gov/sites/default/files/cb/cm2014.pdf

USDHHS. (2015). AFCARS Report \#22: Preliminary FY 2014 Estimates as of July 2015. Retrieved from http://www.acf.hhs.gov/programs/cb/resource/afcars-report-22

Weaver, H. N. (1999). Indigenous people and the social work profession: Defining culturally competent services. Social Work, 44(3), 217-225. doi:https://doi.org/10.1093/sw/44.3.217

Webb-Johnson, G. C., Green, T., \& Beard, K. (2008). Eradicating the fast and furious track to special education: Culturally responsive pre-referral strategies for African American learners. The National Journal of Urban Education and Practice, 3(2), 6982.

Wiegmann, W., Putnam-Hornstein, E., Barrat, V. X., Magruder, J., \& Needell, B. (2014). The invisible achievement gap part 2: How the foster care experiences of California public school students are associated with their education outcomes. Retrieved from http://www.stuartfoundation.org/docs/default-documentlibrary/IAGpart2.pdf?sfvrsn=4

Yan, M. C., \& Wong, Y. L. R. (2005). Rethinking self-awareness in cultural competence: Toward a dialogic self in cross-cultural social work. Families in Society: The Journal of Contemporary Social Services, 86(2), 181-188. doi:https://doi.org/10.1606/1044$\underline{3894.2453}$

Zetlin, A. (2006). The experiences of foster children and youth in special education. Journal of Intellectual and Developmental Disability, 31(3), 161-165. doi:https://doi.org/10.1080/13668250600847039 
Zetlin, A., Weinberg, L., \& Kimm, C. (2004). Improving education outcomes for children in foster care: Intervention by an education liaison. Journal of Education for Students placed at Risk, 9(4), 421-429. doi:https://doi.org/10.1207/s15327671espr0904_5

\section{Author note:}

Address correspondence to: Tonika Duren Green, San Diego State University, Department of Counseling and School Psychology, North Education Room 193, 5500 Campanile Drive, San Diego, CA 92182-1179, 619-594-4467, tduren@mail.sdsu.edu 